\title{
Orígenes de la asociación latinoamericana de Sociología: algunas notas através de la visión de Alfredo Poviña
}

ADRIÁN SCRIBANO

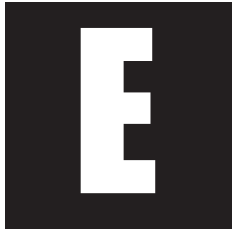

ste articulo no es sobre Alfredo Poviña, pues ese trabajo hubiera demandado revisar una producción bibliográfica muy extensa y prácticamente desconocida; tampoco es una historia de los orígenes de ALAS, lo cual hubiera exigido una tarea de reconstrucción histórica y teórica que excedía las fuerzas y recursos disponibles. El presente texto pretende mostrar, a través de la narración de Alfredo Poviña, la posible atmósfera de los primeros Congresos de ALAS. No se limita a una mera reproducción de los dichos del autor, sin embargo a partir de éstos últimos, por supuesto parciales e interesados, se intentan plantear de modo muy preliminar algunas preguntas que posibiliten continuar la indagación sobre la génesis de ALAS.

En primer lugar, se caracteriza sintéticamente al narrador a través de su curriculum vitae. En segundo lugar, se reproducen algunos textos que posibilitan conocer la Fundación de ALAS. En tercer lugar, se presentan brevemente algunos datos sobre los seis primeros congresos de ALAS. En cuarto lugar, se reseña la idea de Poviña sobre la sociología y se finaliza con una breve sistematización de los nudos centrales que emergen del trabajo, y que posibilitarían una indagación más adecuada sobre los orígenes de

"Doctor en Filosofia de la Universidad de Buenos Aires. Profesor Titular de la Universidad Nacional de Villa Maria, Córdoba - Argentina. 
ALAS.

El presente trabajo es muy sencillo y tiene un carácter provisional y preliminar; sólo busca encender algunas luces que permitan explorar el pasado para que su oclusión no deforme el futuro, bajo el convencimiento de que la sociología debe ser una disciplina científica que hace de la vigilancia epistémica y la reflexividad sus actividades centrales.

\section{1.- ¿Quién fue Alfredo Poviña?}

Cuando comencé a trabajar en este artículo me enteré que Alfredo Poviña (según su propio CV) fue decano de la Facultad de Filosofía y Humanidades de la Universidad Nacional de Córdoba durante los años 19621967 y 1977-1982. Como es obvio, mi primer reflejo fue no trabajar sobre alguien que ocupara esos cargos en dos de las dictaduras más sangrientas de la historia de la Argentina. Una pocas horas de lectura me convencieron, además, de que "su" sociología se situaba muy lejos de mis intereses académicos y políticos. Sin embargo, en una lectura posterior me di con la sorpresa que estaba frente a un testigo presencial de los orígenes de ALAS y eso me hizo reconsiderar mi primera actitud. Si, más allá de lo que haya sido o no Alfredo Poviña, se presenta como uno de los fundadores de la Asociación Latinoamericana de Sociología, este lugar lo convierte en un punto de convergencia especial para comenzar una arqueología institucional y temática. Me convencí que el ejercicio de una vigilancia epistemológica y crítica reflexiva sobre nuestro presente en tanto asociación de sociología no podía obviar esta visión sobre los orígenes, es por eso que hay que comenzar ubicando al narrador en el campo de la sociología de su época.

Entre los datos que contiene la presentación de su curriculum vitae "Alfredo Poviña. Una Síntesis" (1982g) son relevantes para este trabajo los siguientes: 
Sociologias, Porto Alegre, ano 7, no 14, jul/dez 2005, p. 50-61

Obtuvo el título de Doctor en Derecho y Ciencias Sociales en la Universidad Nacional de Córdoba en 1930 con una tesis sobre "Sociología de la Revolución".

En el mismo año fue profesor suplente de Sociología por concurso en la Facultad de Derecho y Ciencias Sociales de la Universidad Nacional de Córdoba.

Fue profesor adjunto de Sociología por concurso en la Facultad de Filosofía y Letras de la Universidad de Buenos Aires en 1939 y Titular por concurso de la misma Cátedra entre 1948 y 1952.

Entre 1955 y 1970 ocupó las Cátedras de Sociología en las facultades de Derecho y Ciencias Sociales y de Filosofía y Humanidades de la Universidad Nacional de Córdoba.

Presidente de ALAS entre 1950 y 1964 y también presidente del Instituto de Internacional de Sociología entre 1963 y 1969.

Publico más de 20 libros y unos 170 artículos en revistas especializadas y periódicos.

Como puede observarse, y más allá de preferencias y simpatías, Poviña ocupó una posición privilegiada en el campo y desde ella se puede comenzar un rastreo de la génesis del mismo.

\section{2.- La Fundación y el sentido de ALAS}

Este apartado busca representar esquemáticamente qué significaba ALAS para nuestro narrador. Se selecciono rastrear algunas de sus definiciones y lo qué el presenta como el símbolo de la Asociación. Es posible que entre la multiplicidad de sentidos que se anudaron en torno a ALAS estas líneas ayuden a descifrar algunos elementos para comprender su pasado.

2.1 ¿Qué es ALAS?

Un tema interesante que emerge en los textos consultados es la visión de Poviña sobre lo que era ALAS desde su posición de fundador y presiden- 
te. Según este autor ALAS nace el 7 de septiembre de 1950 en Zürich en un encuentro ocasional de diez sociólogos quienes -aparentemente en el Congreso Internacional de Sociología- deciden su fundación.

Más allá de lo que indica el estatuto, que de acuerdo a nuestro autor se aprueba en Buenos Aires en el primer Congreso, en su discurso como presidente de ALAS ante el VII Congreso efectuado en Colombia, Poviña afirma:

ALAS ...no es la obra personal de nadie, ni tampoco una institución de carácter ejecutivo; pero sí es una incitación permanente y una presencia activa en toda América (1982c, p. 352).

En ALAS ... Hay profesionales de las sociología y hay aprendices de sociólogos, y más sentimos esto que aquello. Pero el problema no está en darse cada uno su ubicación, en auto-rotularse, ${ }^{1}$ sino en hacer obra efectiva y dejar para la historia el juicio final (1982c, p. 352).

ALAS ...se mantiene de modo permanente en el plano de sus preocupaciones, referente al estudio los problemas de América Latina, enfocados con un doble lente: el ángulo sociológico, y el de hacerlo, no solamente 'para contar árboles' -que naturalmente hay que contarlos- sino también para mirar el bosque en su conjunto y en su perspectiva, sobre la base de que el problema de saber cuántos son y cómo son, ${ }^{2}$ da pie para hacer una sociología teórica, general y doctrinaria, con un abierto sentido universal (1982c, p. 354).

\footnotetext{
1 Sin duda el material consultado, no solamente el citado, en este trabajo abre las puertas para una reconsideración crítica del así llamado período de "Cátedras" en la sociología de América Latina, que en una primera instancia se presenta como fuente muy rica para entender la posterior "Sociología Científica".

2 Es muy interesante observar cómo Poviña hace alusión en varios textos a Gini y "las matemáticas en sociología" con un interés metodológico y político académico muy evidente, lo que muestra -en contra de lo que piensan algunos- e I lugar que la metodología tenia en esos años y esos personajes.
} 
Es posible entrever que hay tres rasgos centrales que definían ALAS para uno de sus fundadores: a) la flexibilidad institucional, b) la apertura a la diversidad de experiencias y formaciones y c) su especificidad problemática.

Es observable también, como veremos más adelante, que, desde la mirada que hace pública nuestro narrador, ALAS nace con la intención de ser un espacio para albergar a todos aquellos que, de un modo u otro, "hacen sociología".

\subsection{De metáforas y símbolos}

Uno de los elementos más llamativos en esta exploración por los orígenes de ALAS fue el encuentro con un símbolo de la Asociación seleccionado por los fundadores: La Victoria de Samotracia. ${ }^{3}$ La narrativa de Poviña adquiere caracteres metafóricos para expresar qué es ALAS a través de la explicitación del significado de La Victoria.

En el Congreso de Caracas nuestro autor enfatiza

...dejamos cumplido el mandato que recibiéramos en Zürich, en diez años de intensa y paciente acción, y que damos ya por concluido, en la renovación de autoridades; cual es el de unir, bajo las alas de la Victoria de Samotracia, símbolo adoptado por nosotros para la institución, a los sociólogos, investigadores, autores y profesores de toda América Latina (1982d, p. 359).

Mientras que en Quito había afirmado que

...Vocación y presencia inspiran básicamente la existencia de ALAS y se mantiene a través del tiempo en la obra realizada. Nuestra institución no cuenta con apoyo oficial permanente, ni nacional o privado, ni de fundación o institución alguna. No hemos pedido, tanto 
por dignidad, como porque sentimos que su potencia no está en el campo económico, sino en las "ALAS" de la Victoria de Samotracia, que es su símbolo, como expresión de su ideal y destino. Ha nacido de un modo espontáneo, con las alas abiertas, para cobijar a todos los sociólogos que buscan su amparo (1982c, p. 352).

Es evidente que ALAS representa la libertad que da la no sujeción, la presencia de pensamiento y acción, su capacidad de volar autónomamente. La sociología nace, al menos en tanto Asociación y más allá de las intenciones de sus creadores, buscando dar ALAS al continente. La contextualización y genealogía de este símbolo y de sus potenciales trasposiciones metafóricas parecen ser una buena pista para una sociogénesis del campo sociológico en el continente. ${ }^{4}$

\section{3- De congresos y fundadores: fechas, temas y lugares}

A pesar de la escasa información que Poviña brinda en los textos consultados, es posible observar cómo aquellos diez fundadores se empeñaron en la consecución de los Congresos de ALAS. Según los textos aludidos, los seis (6) primeros congresos y la mayoría de sus respectivos presidentes conformaron el "Grupo Zürich." ${ }^{5}$ La lista de lugares y presidentes es la siguiente:

1ㅡ. Alfredo Poviña (Buenos Aires) (Fundador)

2 ${ }^{\text {a }}$ Carneiro Leao (Río de Janeiro/ San Pablo ${ }^{6}$ )

\footnotetext{
4 De acuerdo a la narración de Poviña, ALAS fue la primera Asociación en todo el continente.

5 Se adopta la denominación Grupo Zürich para indagar posteriormente las discontinuidades con el llamado Grupo de Palo Alto o Grupo Latinomericano para el desarrollo de la sociología creado en California en 1961, entre otros cfr. Marsal ob. Cit., p. 171 nota 13.

6 Según Poviña el Secretario General del Congreso fue Odorico Pires Pinto.
} 
3a Luis Bossano (Quito) (Fundador) 4a Astolfo Tapia Moore ${ }^{7}$ (Santiago de Chile) (Fundador)

5a Isaac Ganón ${ }^{8}$ (Montevideo)

6을 Rafael Caldera (Caracas) (Fundador)

Una reconstrucción parcial de las fechas y temáticas abordadas por los Congresos ${ }^{9}$ puede ser realizada de la siguiente manera:

1. Del 20 al 25 de septiembre de 1951 se realiza en Buenos Aires el Primer congreso cuyo tema fue "...los problemas fundamentales de la sociología latino americana." (1982c, p. 352)

2. Del 10 a 17 de Julio de 1953 se realiza en Río de Janeiro y en San Pablo el Segundo congreso donde se trabajaron los siguientes temas: “...Sociología general, estructura social, contactos culturales, y problemas sociales y sociología aplicada." (1982c, p. 353)

3. Del 12 al 18 de Octubre de 1955 se realizó en Quito el Tercer congreso donde se abordaron los siguientes ejes: “...Bases para un programa de la enseñanza de la Sociología en Latinoamérica, teoría de las clases sociales y su realización en América, la sociología rural en la América Latina; los problemas de la educación desde un punto de vista sociológico; problemas de mestizaje y realidad indígena en América". (1982c, p. 353)

4. Del 6 al 13 de Julio de 1957 se efectúa en Santiago de Chile el Cuarto congreso cuyo, "...Temario incluía los problemas relativos a la teoría y métodos de la sociología, sociología política, sociología rural, y la industrialización de América Latina, desde el punto de vista sociológico". (1982c, p. 353)

\footnotetext{
7 Tapia Moore fue, según Poviña, Vice-Presidente de ALAS desde su fundación.

8 Fundador de la Asociación Internacional de Sociología según una noticia aparecida en La Republica ob. Cit 9 Un elemento importante a la hora de la reconstrucción de la historia de los seis primeros congresos es que, de acuerdo a lo relatado por Poviña, cada uno de ellos publicó sus Actas.
} 
5. Del 6 al 11 de Junio de 1959 se realizó en Montevideo el Quinto congreso que trabajó las siguientes temáticas: “...Efectos sociales del desarrollo económico; sociografía de la vivienda rural y urbana; metodología de la investigación en el área de Latino América; partidos políticos, clases sociales y grupos de presión". (1982c, p. 354)

6. Del 7 al 14 de Abril de 1961 se realizó en Caracas el Sexto congreso “...Su temario fue la investigación científica sociológica en América Latina; partidos políticos y sociología electoral; y el cambio social en el Continente". (1982c, p. 354)

Como es fácil de advertir, entre el primer y sexto Congreso han pasado once años y las temáticas, más allá de que reflejan parcialmente las problemáticas locales, van recorriendo los profundos cambios que el continente va sufriendo. Si bien lo teórico y lo metodológico tienen, de una manera u otra, un lugar central, los "problemas latinoamericanos" ocupan el puesto de ejes vertebradores de las discusión. Como así también, además de aparecer siempre "la sociología" o "lo sociológico" como tópico a discutir, su cariz específico lo da la preocupación de su "aplicabilidad" a los procesos sociales.

\section{4.- ¿Qué sociología?}

Otro tema interesante, hallado en esta primera reconstrucción, es la mirada de Poviña sobre qué significa la sociología en Latinoaméricana en sus discursos como presidente de ALAS y también del Congreso del Instituto Internacional de Sociología efectuado en Córdoba.

En su discurso en Caracas sostenía:

...La sociología es un saber que posee vigencia histórica permanente, mediante la cualidad de ver renovada de un modo incesante, su problemática, surgiendo las cuestiones, como expresión de la realidad 
Sociologias, Porto Alegre, ano 7, no 14, jul/dez 2005, p. 50-61

contemporánea y de la época. Es siempre ciencia del presente... (1982c, p. 355).

Además, en su discurso en Córdoba, afirmaba que la sociología ...es una disciplina del presente. Su objeto son los problemas actuales del quehacer colectivo. Es la respuesta a las incitaciones del medio social. Es la presencia científica para salvar el compromiso del hombre frente a la agresión de la realidad. Le da el arma de lucha, el plan de combate para enfrentarse con la existencia;... (1982b, p. 337).

Agregando que, “...La sociología es la ciencia que se está haciendo constantemente sobre la base de la actualidad. No puede dormir sobre sus laureles; vive "tocando arrebato", convocando a sus especialistas a la plaza pública,..." (1982b, p. 338).

Más allá de las ideas y conceptos propios de la sociología que cultivara Poviña, estos párrafos dejan entrever tres rasgos del quehacer sociológico que permitirían servir de guías para una indagación posterior: la sociología como ciencia del presente, la relación directa entre trabajo sociológico y estructuración social y su "destino" de participación en los espacios públicos. Se hace evidente que la relación entre "política" y sociología fue desde lo inicios una preocupación de la Asociación.

Es muy probable que la mirada de nuestro autor no haya sido hegemónica en la sociología latinoamericana, pero su visualización señala claramente sobre la posibilidad de hacerla pública. Es decir, el hecho que Poviña lo diga en público indica, al menos, la tolerancia pública que tenían las ideas expresadas y éstas parecen reconstruir, por lo menos potencialmente, la visión sobre lo que las "sociologías de cátedra" pensaron. 


\section{5.- Aquel pasado, nuestro futuro}

Más allá del estado preliminar de este trabajo, es posible esbozar algunas notas en tono de preguntas que permitan continuar la indagación sobre los orígenes de ALAS.

En primer lugar, es muy interesante encontrarse que en la década de los 50 la "sociología de cátedra" se da a sí misma una organización institucional de carácter regional, lo cual habla claramente de un aspecto pocas veces abordado por la historiografía disciplinar contemporánea. Un rastreo más pertinente sobre lo que aquí se denominó "Grupo Zürich" puede ser una pista interesante para ampliar las visiones existentes.

En segundo lugar, las temáticas abordadas por los Congresos posibilitan entender cómo la sociología en América Latina, más allá y más acá de su practicantes, ha estado ligada a las problemáticas sociales de mayor preocupación epocal, lo que impulsaría a indagar, en un seguimiento sociohistórico, las permanentes -y obvias- relaciones entre teoría social y estructura social.

En tercer lugar, y a partir de lo desarrollado, puede apreciarse cómo aquella sociología "como ciencia del presente" de un modo u otro ha generado el actual presente sociológico. En muchas ocasiones, y a veces de modo legítimo, en la historia de la sociología se pasa por alto la "etapa" representada en los que "enseñaban" sociología; quizás la historia de ALAS permita reconstruirla de modo más adecuado. Esa reconstrucción se presenta como importante para observar con mayor detenimiento el surgimiento de la llamada "sociología científica", tópico central para un saber sobre la genealogía disciplinar.

Para finalizar, es posible advertir que aquel pasado debe ser conectado con nuestro futuro de manera que se pueda desocultar lo que ha quedado reprimido en el olvido y hacerlo crítico. Todos aquellos que creemos que 
Sociologias, Porto Alegre, ano 7, no 14, jul/dez 2005, p. 50-61

el aporte de la sociología -por distintas vías- puede ser fundamental para los procesos emancipatorios tenemos la obligación de hacer de esta ciencia una que no trabaje sobre el olvido y que vea en el presente un pista para entender el futuro.

\section{Referencias}

MARSAL, J. Cambio Social en América Latina. Bs.As: Solar/Hachette, 1967.

LA REPUBLICA EN LA RED. Hoy realizan homenaje a Ganón en la Sala Maggiolo. 2000. Disponível em: < http://www.diariolarepublica.com/2001> Acesso em: 22/ 12/04 out. 2001.

POVIÑA, A. Historia de la Sociología Latinoamericana. México: FCE, 1941.

POVIÑA, A. Sociológica. de Teoría y de Historia. Córdoba: Editorial Assandri, 1982a. Vol. I y II Ediciones de la Academia Nacional de Derecho y Ciencias Sociales.

POVIÑA, Alfredo. El I.I.S. en Córdoba-Madrid-Roma In: POVIÑA, Alfredo. Sociológica. De Teoría y de Historia. Vol. I y II Ediciones de la Academia Nacional de Derecho y Ciencias Sociales. Córdoba: Editorial Assandri, 1982b. p. 335-349.

POVIÑA, Alfredo. A.L.A.S. y sus siete congresos In: POVIÑA, Alfredo. Sociológica. De Teoría y de Historia. Vol. I y II Ediciones de la Academia Nacional de Derecho y Ciencias Sociales. Córdoba: Editorial Assandri, 1982c. p. 351-357.

POVIÑA, Alfredo. Caldera y el Congreso de Caracas In: POVIÑA, Alfredo. Sociológica. De Teoría y de Historia. Vol. I y II Ediciones de la Academia Nacional de Derecho y Ciencias Sociales. Córdoba: Editorial Assandri, 1982d. p. 359-361.

POVIÑA, Alfredo. Aquí Jose Medina Echavarria y allá dos notas finales In: POVIÑA, Alfredo. Sociológica. De Teoría y de Historia. Vol. I y II Ediciones de la Academia Nacional de Derecho y Ciencias Sociales. Córdoba: Editorial Assandri, 1982e. p. 364-365.

POVIÑA, Alfredo. Historia y Futuro de S.A.S. In: POVIÑA, Alfredo. Sociológica. De Teoría y de Historia. Vol. I y II Ediciones de la Academia Nacional de Derecho 
y Ciencias Sociales. Córdoba: Editorial Assandri, 1982f. p. 367-483.

POVIÑA, Alfredo. Una hoja de Vida. Un curriculum y una síntesis In: POVIÑA, Alfredo. Sociológica. De Teoría y de Historia. Vol. I y II Ediciones de la Academia Nacional de Derecho y Ciencias Sociales. Córdoba: Editorial Assandri, 1982g. p. 411-413.

Recebido: 28/02/2005

Aceite final: 05/05/2005

\section{Resumo}

El presente articulo pretende mostrar, a través de la narración de Alfredo Poviña, la posible atmósfera de los primeros Congresos de ALAS. No se limita a una mera reproducción de los dichos del autor, sin embargo a partir de éstos últimos, por supuesto parciales e interesados, se intentan plantear de modo muy preliminar algunas preguntas que posibiliten continuar la indagación sobre la génesis de ALAS. (Asociación Latinoamericana de Sociología)

Para logra la meta propuesta se sintetizan algunos textos que posibilitan conocer la Fundación de ALAS. Se presentan brevemente algunos datos sobre los seis primeros congresos de ALAS. Se reseña la idea de Poviña sobre la sociología y se finaliza con una breve sistematización de los nudos centrales que emergen del trabajo, y que posibilitarían una indagación más adecuada sobre los orígenes de ALAS.

El presente ensayo es muy sencillo y tiene un carácter provisional y preliminar; sólo busca encender algunas luces que permitan explorar el pasado para que su oclusión no deforme el futuro, bajo el convencimiento de que la sociología debe ser una disciplina científica que hace de la vigilancia epistémica y la reflexividad sus actividades centrales.

Palabras-claves: congresos ALAS, misión, metáfora, sentido. 


\section{The origins of the Latin American Sociology Association: a few notes through the outlook of Alfredo Poviña}

\section{Adrián Scribano}

This article intends to show, through Alfredo Poviña' narrative, the possible atmosphere of the first congresses of the Latin American Sociology Association (ALAS). It is not restricted to a mere reproduction of the authors words; rather, based on them - which are seen as partial and interested - it attempts to show in a very preliminary way a few questions that allow to move on with the interrogation about the genesis of ALAS.

To achieve the proposed aim, some texts are summarized, which allow to get to know ALAS' foundation. Data are briefly presented about the six first ALAS congresses. Poviña's idea of sociology is reviewed, closing with a brief systematization of the core points that emerge from his work, which would allow a more adequate interrogation about the origins of ALAS.

This essay is very simple and has a provisional and preliminary character. It only seeks to shed some light to explore the past in order for its occlusion not to deform the future, based on the conviction that sociology must be a scientific discipline that makes epistemic vigilance and reflexivity its central activities.

Key words: ALAS congresses, mission, metaphor, meaning 